\title{
Polymorphisms of CD16A and CD32 Fcy receptors and circulating immune complexes in Ménière's disease: a case-control study
}

\author{
José A Lopez-Escamez ${ }^{1,2^{*}}$, Pablo Saenz-Lopez ${ }^{3}$, Irene Gazquez ${ }^{1,3}$, Antonia Moreno ${ }^{3}$, Carlos Gonzalez-Oller , \\ Andrés Soto-Varela ${ }^{5}$, Sofía Santos ${ }^{5}$, Ismael Aran ${ }^{6}$, Herminio Perez-Garrigues ${ }^{7}$, Águeda Ibañez ${ }^{4}$ \\ Miguel A Lopez-Nevot ${ }^{3}$
}

\begin{abstract}
Background: Autoimmune diseases with elevated circulating autoantibodies drive tissue damage and the onset of disease. The Fcy receptors bind IgG subtypes modulating the clearance of circulating immune complexes (CIC). The inner ear damage in Ménière's disease (MD) could be mediated by an immune response driven by CIC. We examined single-nucleotide polymorphism (SNPS) in the CD16A and CD32 genes in patients with MD which may determine a FCy receptor with lower binding to $\mathrm{CIC}$.

Methods: The functional CD16A (FcyRllla*559A > C, rs396991) and CD32A (FcyRlla*519A > G, rs1801274) SNPs were analyzed using PCR-based TagMan Genotyping Assay in two cohorts of 156 mediterranean and 112 Galicia patients in a case-control study. Data were analyzed by $\chi^{2}$ with Fisher's exact test and Cochran-Armitage trend test (CATT). CIC were measured by ELISA for C1q-binding CIC.

Results: Elevated $\mathrm{CIC}$ were found in $7 \%$ of patients with MD during the intercrisis period. No differences were found in the allelic frequency for rs396991 or rs 1801274 in controls subjects when they were compared with patients with MD from the same geographic area. However, the frequency of AA and AC genotypes of CD16A (rs396991) differed among mediterranean and Galicia controls (Fisher's test, corrected $p=6.9 \times 10^{-4}$ for AA; corrected $p=0.02$ for $A C$ ). Although genotype $A C$ of the CD16A receptor was significantly more frequent in mediterranean controls than in patients, [Fisher's test corrected $p=0.02 ; \mathrm{OR}=0.63(0.44-0.91)$ ], a genetic additive effect for the allele $C$ was not observed (CATT, $p=0.23$ ). Moreover, no differences were found in genotype frequencies for rs396991 between patients with MD and controls from Galicia (CATT, $p=0.14$ ). The allelic frequency of CD32 (rs 1801274) was not different between patients and controls either in mediterranean ( $p=0.51$ ) or Galicia population $(p=0.11)$.
\end{abstract}

Conclusions: Elevated $\mathrm{CIC}$ are not found in most of patients with MD. Functional polymorphisms of CD16A and CD32 genes are not associated with onset of MD.

\section{Background}

Ménière's disease (MD) is a chronic disease defined by recurrent spells of vertigo associated with sensorineural hearing loss and tinnitus or aural fullness. Different autoimmune diseases share susceptibility loci, but consistent associations with multiple autoimmune disorders

\footnotetext{
* Correspondence: antonio.lopezescamez@ephpo.es

'Otology \& Neurotology Group CTS495, Department of Otolaryngology,

Hospital de Poniente, El Ejido, Almería, Spain

Full list of author information is available at the end of the article
}

have been restricted to three genes: the human leukocyte antigen (HLA) DRB1 gene, the PTPN22 gene encoding lymphoid tyrosine phosphatase LYP and the gene encoding cytotoxic T lymphocyte-associated 4 (CTLA-4) receptor [1]. Autoimmune mechanisms appear to be associated with the pathogenesis of some types of sensorineural hearing loss (SNHL), [2,3] including rapidly progressive bilateral SNHL (autoimmune inner ear disease), [4] sudden SNHL [5] and MD [6-8]. Allelic variants of the HLA class II gene DRB1 and the

\section{Biomed Central}


functional polymorphism $1858 \mathrm{C}>\mathrm{T}$ of the PTPN22 gene have been associated to bilateral MD in mediterranean population, suggesting an autoimmune process [9].

Diversity of populations may explain differences in HLA-DRB1 associations found in British [10], German [11], Japanese [12], Korean [13] or Spanish patients with MD [14]. Moreover, the response to steroids therapy and the finding of elevated levels of circulating immune complexes (CIC) in some patients with $\mathrm{MD}$, especially in the active phase, has supported the hypothesis of autoimmunity in MD $[15,16]$. A decrease in CIC clearance could determine an increase of CIC levels which are deposited in the blood vessels of the endolymphatic sac, resulting in inflammation with increase in vascular permeability and the development of endolymphatic hydrops [16].

The Fc $\gamma$ receptors CD16A and CD32A connect the innate and the adaptative immune response by transmitting activating signals to natural killer lymphocytes and myeloid cell upon recognition of Fc of IgG [17].

CD32A (Fc $\gamma$ RIIa) exhibits low affinity for monomeric IgG, but binds IgG CIC efficiently. Two genes and two transcripts of Fc $\gamma$ RIII have been described (Fc $\gamma$ RIIIa, and IIIb), which also bind IgG CIC and Fc $\gamma$ RIIIa (CD16A) has intermediate affinity for monomeric IgG and it is involved in the removal of CIC [18]. CD32A is expressed in all myeloid cells, platelets, and endothelial cells, whereas CD16A is present on monocytes, macrophages, NK cells and $\gamma / \delta$ T cells [17].

Fc $\gamma$ receptors subclasses display functionally relevant genetically determined polymorphisms. So, Fc $\gamma$ RIIa displays a $\mathrm{G}$ to A single nucleotide polymorphism (SNP) at nucleotide 519 in the region specifying its ligand binding domain, causing an arginine $(\mathrm{R})$ to histidine $(\mathrm{H})$ amino acid substitution at position 131 (rs1801274). The Fc $\gamma$ RIIa-H131 allotype shows higher binding efficiency for human IgG2 and IgG3 isoforms, compared to Fc $\gamma$ RIIa-R131. The Fc $\gamma$ RIIIa gene displays a C to A substitution in exon 4 at nucleotide 559, resulting in a valine $(\mathrm{V})$ to phenylalanine (F) substitution at amino acid position 158 (rs396991) [19]. IgG-induced NK cell activity is increased among Fc $\gamma$ RIIIa-V/V158 donors, compared to FcyRIIIa-F/F158 individuals, due to a higher affinity of the former allotype for IgG1, IgG3 and IgG4 $[18,20]$. These low binding phenotypes has been associated with susceptibility to recurrent viral infections, rheumatoid arthritis [21,22] and systemic lupus erythematosus [23] and are clinically relevant because they modify the clinical course and the response to therapy of several human diseases [24].

The aim of this study was to analyze the Fc $\gamma$ RIIa*519A $>\mathrm{G}$ and Fc $\gamma$ RIIIa*559A > C SNPs in the Fc receptor cluster in patients with definite MD.

\section{Methods}

\section{Subjects}

DNA Samples from 268 unrelated patients with MD and 770 controls from two ethnically defined regions were included in a prospective multicenter study between January 2004 and December 2009. All patients were diagnosed according to the diagnostic scale for MD of the American Academy of Otolaryngology- Head and Neck Surgery (AAO-HNS) [25]. Group 1 consisted of 156 Caucasian patients from the east and southeast areas of Spain (85 unilateral, 71 bilateral MD) that were compared with 626 controls from the same area. Group 2 was recruited to replicate the results of group 1 and included 112 (47 unilateral, 65 bilateral MD) Caucasian patients and 144 controls from Galicia (northwest of Spain). Five centers recruited samples from patients with MD for this study: Hospital La Fe from Valencia, Hospital Virgen de las Nieves from Granada, Hospital de Poniente from El Ejido, Almeria (group 1) and Hospital Santiago de Compostela and Hospital de Pontevedra (group 2). Controls for group 1 were unrelated Caucasian volunteer blood donors at Almeria and Granada; controls for group 2 were provided by the Spanish DNA BioBank http://www.bancoadn.org. The selection of controls was matched by age and gender in both populations. Caucasian subjects with a different origin (Maghreb, Romani minority) were excluded to avoid a substructure bias in the controls (Table 1).

The subject's informed consent was obtained to participate in the study according to the Declaration of Helsinki and the local Institutional Board approved the study. The clinical features and HLA-DRB1 and DQB1 genotyping of some patients with MD from both groups were previously reported [14].

\section{DNA extraction and genotyping}

All genomic procedures were carried out at Department of Immunology, Hospital Virgen de las Nieves, Granada, Spain. Total genomic DNA was automatically isolated from peripheral blood of patients and healthy controls

Table 1 Baseline characteristics of case and control subjects

\begin{tabular}{|c|c|c|c|c|}
\hline \multirow[t]{2}{*}{ Variable } & \multicolumn{2}{|c|}{ Southeast population } & \multicolumn{2}{|c|}{ Northwest population } \\
\hline & MD & Control & MD & Control \\
\hline Subjects & 156 & 626 & 112 & 144 \\
\hline Female gender (\%) & 53.8 & 59.7 & 50.0 & 51.4 \\
\hline \multicolumn{5}{|c|}{ Age (years) } \\
\hline Mean & 56.1 & 38.0 & 55.5 & 37.2 \\
\hline Median & 56 & 37 & 58 & 38,5 \\
\hline Range & $15-88$ & $19-68$ & $12-79$ & $18-64$ \\
\hline SD & 13.1 & 9.5 & 13.8 & 13.1 \\
\hline
\end{tabular}


using the M-48 robot (Genovision) and the MagAttract DNA Blood Mini M48 (192) kit from Qiagen. The genotyping of the Fc $\gamma$ RIIa*519A > G (rs1801274) and Fc $\gamma$ RIIIa*559A > C (rs396991) SNPs were performed using a predeveloped TaqMan SNP Genotyping Assays (Applied Biosystems, Foster City, CA). The PCR reaction was carried out using the Assays-on-Demand SNP genotyping kit (AB). SNPs amplification assays were used according to the manufacturer's instructions. In short, $5 \mu$ l of reaction solution containing 10ng of DNA was mixed with $2.5 \mu \mathrm{l}$ of $2 \times$ TaqMan Universal PCR Mix (AB), $0.05 \mu \mathrm{l}$ of predeveloped assay reagent from the SNP genotyping product $(\mathrm{AB})$ containing two primers and two MGB-Taqman probes and 1,45 $\mu \mathrm{l}$ of desionizated water. Reaction conditions consisted of preincubation at $50^{\circ} \mathrm{C}$ for 2 minutes and at $95^{\circ} \mathrm{C}$ for 10 minutes, followed by 40 cycles at $95^{\circ} \mathrm{C}$ for 15 seconds and at $60^{\circ} \mathrm{C}$ for 1 minute. Amplifications and analysis were performed in an ABI Prism 7500 Sequence Detection System (AB) using the SDS 1.4 software for allelic discrimination $(\mathrm{AB})$.

\section{Determination of circulating immunocomplexes}

Serum samples from 331 patients (85 mediterranean and 203 Galicia patients) were obtained to determine CIC concentrations. So, an Autostat ${ }^{\mathrm{TM}} \mathrm{II}$ test for $\mathrm{C} 1 \mathrm{q}$ CIC kit (HYCOR, Agilent Technologies, Amstelveen, The Netherlands) was used to detect immune complexes containing both C1q and IgG in a Hytec 288 Plus System (HYCOR). Positive and negative controls and reference values were provided by the manufacturer $(0-40 \mu \mathrm{g} / \mathrm{ml})$.

\section{Statistical analysis}

Allelic and genotype frequencies were calculated by direct counting. Hardy-Weinberg equilibrium was tested for each SNP among controls. For $2 \times 2$ contingency tables of allele frequencies of patients with MD and controls, odds ratios (ORs) and 95\% confidence intervals (95\% CI), $\chi^{2}$ test and Fisher's exact test were calculated to determine the exact two-sided p-values using SPSS Software (SPSS Inc., Chicago, IL, USA). Genotype frequencies were compared for each of the $2 \times 3$ contingency tables by Cochran-Armitage trend test, which may have more power than Fisher's exact test if a trend exists across genotype categories under the additive genetic effect model. Probability values $(p)$ were corrected by multiplying the $p$ value by the number of genotypes compared. p-values lower than 0.05 were considered statistically significant.

\section{Results}

The CD32 (Fc $\gamma$ RIIa*519A > G) and CD16A (Fc $\gamma$ RIIIa*559A > C) SNPs in the Fc $\gamma$ receptors were selected to investigate their association with MD.
Genotype distributions of both SNPs in mediterranean and Galicia controls exhibited Hardy- Weinberg equilibrium (data not shown), and the minor allele frequencies of all SNPs were over 5\% in controls from both groups.

First, the frequencies of genotypes AA and AC for Fc $\gamma$ RIIIa*559A > C were significantly different in controls from southeast and northwest of Spain (Table 2). So, the genotype AA of Fc $\gamma$ RIIIa (low binding phenotype) is more common in Galicia than in mediterranean population (Fisher's exact test, $\mathrm{p}=6.9 \times 10^{-4}$ ). Second, we compared the genotypes distribution of both SNPs between patients with uni and bilateral MD (Table 3). There was no difference in the genotype of both Fc $\gamma$ RIIa*519A > G and Fc $\gamma$ RIIIa*559A > C SNPs between patients with one or both ears affected either in mediterranean or Galicia population (all, p > 0.05).

The CD32 allelic frequencies (rs1801274) did not differ between patients and controls either in southeast $(\mathrm{p}=0.51)$ or northwest groups $(\mathrm{p}=0.11)$. Moreover, AA and AG genotypes did not increase the risk for MD in any of both populations (Table 4).

In addition, no differences were found in the allelic frequency of CD16A (rs396991) in controls subjects when they were compared with patients with MD from the same geographic area. Although the genotype AC of CD16A receptor was significantly more frequent in mediterranean controls than in $\mathrm{MD}$ patients $(\mathrm{OR}=0.63$ (0.44-0.91), Fisher's test, corrected $\mathrm{p}=0.02)$, a genetic additive effect for the allele $C$ was not observed (Cochcran-Armitage trend test, $\mathrm{p}=0.23$ ). The genotype AA of Fc $\gamma$ RIIIa (rs396991) encoding the Fc $\gamma$ RIIIa-F/F158 phenotype was not associated with MD (95\% CI, 1.042.10 ; corrected $\mathrm{p}=0.06$ ) (Table 5 ). Moreover, we replicated our observations in the northwest group, and no differences were found in genotype frequencies for rs396991 between patients with MD and controls from Galicia (CATT, p = 0.11).

Circulating immunocomplexes were investigated in 331 patients with MD. There was an increase of CIC in 25 patients $(7.6 \%)$. No difference was found in the frequency of elevated CIC between patients with unilateral (7\%) or bilateral involvement $(8.4 \%)$. In addition, we did not found association between elevated CIC and the homozygous genotype AA of Fc $\gamma$ RIIIa either in mediterranean $(\mathrm{p}=0.42)$ or Galicia $(\mathrm{p}=0.64)$ patients in our series.

\section{Discussion}

Our shows that heterogeneity within caucasian population should be consider in genetic association studies. The distribution of frequencies of CD16A genotypes AA and $\mathrm{AC}$ was different in Galicia and mediterranean controls. The genotype frequencies in our Mediterranean 
Table 2 Distribution of rs396991 (CD16A) and rs1801274 (CD32) genotypes and phenotypes in controls subjects from southeast and northwest populations

\begin{tabular}{|c|c|c|c|c|c|}
\hline Genotype & Phenotype & Southeast & Northwest & Fisher exact $p$ values & Corrected $\mathrm{p}$ \\
\hline CD16A & & $N=626(\%)$ & $N=141(\%)$ & & \\
\hline AA & $176 \mathrm{~F} / \mathrm{F}$ & $221(35.3)$ & $73(51.8)$ & $2.3 \times 10^{-4}$ & $6.9 \times 10^{-4}$ \\
\hline$A C$ & $176 \mathrm{~F} N$ & $314(50.2)$ & $54(38.3)$ & $7 \times 10^{-3}$ & 0.02 \\
\hline CC & $176 \mathrm{VN}$ & $91(14.5)$ & $14(9.9)$ & 0.09 & NS \\
\hline CD32 & & $N=349(\%)$ & $N=144(\%)$ & & \\
\hline $\mathrm{AA}$ & $131 \mathrm{R} / \mathrm{R}$ & $95(27.2)$ & $28(19.4)$ & 0.04 & NS \\
\hline$A G$ & $131 \mathrm{R} / \mathrm{H}$ & $162(46.4)$ & $83(57.6)$ & 0.01 & 0.03 \\
\hline GG & $131 \mathrm{H} / \mathrm{H}$ & $92(26.4)$ & $33(22.9)$ & 0.25 & NS \\
\hline
\end{tabular}

Low affinity binding phenotypes are $176 \mathrm{~F} / \mathrm{F}$ and $131 \mathrm{R} / \mathrm{R}$.

controls are identical to frequencies reported in a previous study from the same geographical area [21]. The difference of CD16A with the Galicia population may indicate a differential immunogenetic background between populations.

These two SNPs were chosen because they determine a low binding phenotype for Fc $\gamma$ receptors and their consistent association with rheumatoid arthritis $[21,22]$ and systemic lupus erythematosus [23].

The genotype AC of the Fc $\gamma$ RIIIa*559A > C (CD16A) gene is overrepresented in mediterranean controls and it may confer some protection for MD in mediterranean patients, although the trend test did not confirm an additive effect in homozygous subjects. In addition, the

Table 3 Distribution of CD16a and CD32 genotypes in patients with uni and bilateral MD ( $\chi 2$ test)

\begin{tabular}{cccc}
\hline Southeast group & Unilateral & Bilateral & P value \\
\hline CD16A genotype & $N=85(\%)$ & $N=71(\%)$ & \\
AA & $37(43.5)$ & $33(46.5)$ & 0.91 \\
AC & $33(38.8)$ & $27(38.0)$ & \\
CC & $15(17.6)$ & $11(15.5)$ & \\
CD32 genotype & $\mathrm{N}=85(\%)$ & $\mathrm{N}=71(\%)$ & \\
AA & $21(24.7)$ & $22(31.0)$ & 0.59 \\
AG & $42(49.4)$ & $29(40.8)$ & \\
GG & $22(25.9)$ & $20(28.2)$ & \\
\hline & & & \\
\hline Northwest group & Unilateral & Bilateral & P value \\
\hline CD16A genotype & $\mathrm{N}=45(\%)$ & $\mathrm{N}=65(\%)$ & \\
AA & $17(37.8)$ & $29(44.6)$ & 0.34 \\
AC & $22(48.9)$ & $28(43.1)$ & \\
CC & $6(13.3)$ & $8(12.7)$ & \\
& & & \\
CD32 genotype & $\mathrm{N}=47(\%)$ & $\mathrm{N}=65(\%)$ & \\
AA & $12(25.5)$ & $18(27.7)$ & 0.84 \\
AG & $25(53.2)$ & $36(55.4)$ & \\
GG & $10(21.3)$ & $11(16.9)$ & \\
\hline
\end{tabular}

genotype AA of CD16A was marginally associated with $\mathrm{MD}$ in mediterranean population. However, these finding could not be replicated in the population from Galicia within the same country. The allele A encodes for a V to $\mathrm{F}$ substitution at amino acid position 158, resulting in an Fc $\gamma$ RIIIa allotype with a lower affinity. The lower affinity of this Fc receptor for IgG subclasses may decrease the binding efficiency for IgG1, IgG3 and IgG4 complexes, resulting in a lower clearance of CIC.

We cannot support the hypothesis that Fc $\gamma \mathrm{R}$ polymorphisms determine a CIC-mediated damage in the inner ear of patients with MD, although the efficiency of Fc $\gamma$ R-IgG interaction may predict the efficacy of CIC clearance [17]. A less efficient CIC clearance may lower the threshold for complexes deposition in the vascular endothelium, with the induction of inflammation

Table 4 Frequency of CD32 alleles and genotypes among MD patients and healthy controls (Fisher's exact test)

\begin{tabular}{ccccc}
\hline Southeast & $\begin{array}{c}\text { MD N = } \\
\mathbf{1 5 5}(\%)\end{array}$ & $\begin{array}{c}\text { Controls } \\
\mathbf{N}=\mathbf{3 4 9}(\%)\end{array}$ & OR (95\% Cl) & P value \\
\hline AA & $43(27.7)$ & $95(27.2)$ & $1,03(0.67-1.57)$ & 0.49 \\
AG & $70(45.2)$ & $162(46.4)$ & $0,95(0.65-1.39)$ & 0.43 \\
GG & $42(27.1)$ & $92(26.4)$ & $1,04(0.68-1.59)$ & 0.47 \\
& & & & \\
Allele & $2 n=310(\%)$ & $2 n=698(\%)$ & $1,00(0.77-1.31)$ & 0.51 \\
A & $156(50.3)$ & $352(50.4)$ & & \\
G & $154(49.7)$ & $346(49.6)$ & & \\
\hline
\end{tabular}

\begin{tabular}{ccccc}
\hline Northwest & $\begin{array}{c}\text { MD N = } \\
\mathbf{1 1 2}(\%)\end{array}$ & $\begin{array}{c}\text { Controls } \\
\mathbf{N}=\mathbf{1 4 4}(\%)\end{array}$ & OR (95\% Cl) & P value \\
\hline AA & $30(26.8)$ & $28(19.4)$ & $1,52(0.84-2.72)$ & 0,11 \\
AG & $61(54.5)$ & $83(57.6)$ & $0.88(0.53-1.45)$ & 0.35 \\
GG & $21(18.8)$ & $33(22.9)$ & $0.77(0.42-1.43)$ & 0.26 \\
& & & & \\
Allele & $2 n=224(\%)$ & $2 n=228(\%)$ & $1.25(0.88-1.79)$ & 0.11 \\
A & $121(54.0)$ & $139(48.3)$ & & \\
G & $103(46.0)$ & $149(51.7)$ & & \\
\hline
\end{tabular}


Table 5 Frequency of CD16A alleles and genotypes among MD patients and healthy controls

\begin{tabular}{cccccc}
\hline Southeast & MD N = 156 (\%) & Controls $\mathbf{N}=\mathbf{6 2 6}(\mathbf{\%})$ & OR (95\% Cl) & Fisher's exact $\mathbf{p}$ values & Corrected $\mathbf{p}$ \\
\hline AA & $70(44.9)$ & $221(35.3)$ & $1.49(1.05-2.12)$ & 0.018 & 0.006 \\
AC & $60(38.5)$ & $314(50.2)$ & $0.62(0.43-0.89)$ & 0.29 & NS \\
CC & $26(16.7)$ & $91(14.5)$ & $1.17(0.73-1.89)$ & & 0.13 \\
Allele & $2 n=312(\%)$ & $2 n=1252(\%)$ & $1.17(0.91-1.52)$ & & NS \\
A & $200(64.1)$ & $756(60.4)$ & & & \\
C & $112(35.9)$ & $496(39.6)$ & & & \\
\hline
\end{tabular}

\begin{tabular}{cccccc}
\hline Northwest & MD N = 110 (\%) & Controls $\mathbf{N}=\mathbf{1 4 1}(\mathbf{\%})$ & OR (95\% Cl) & Fisher's exact $\mathbf{p}$ values & Corrected $\mathbf{p}$ \\
\hline AA & $46(41.8)$ & $73(51.8)$ & $0.67(0.40-1.11)$ & 0.07 & NS \\
AC & $50(45.5)$ & $54(38.3)$ & $1.34(0.80-2.23)$ & 0.15 & NS \\
CC & $14(12.7)$ & $14(9.9)$ & $1.32(0.60-2.91)$ & & 0.31 \\
Allele & $2 n=220(\%)$ & $2 n=282(\%)$ & $0.75(0.51-1.09)$ & & NS \\
A & $142(64.5)$ & $200(70.9)$ & & & \\
C & $78(35.5)$ & $82(29.1)$ & & & \\
\hline
\end{tabular}

No additive effect was observed in homozygous subjects with Cochran-Armitage trend test in the southeast $(p=0.23)$ and the northwest group ( $p=0.14$ ).

observed in autoimmune diseases as rheumatoid arthritis [20].

The rs 396991 of CD16A has been associated with rheumatoid arthritis [21,22], systemic lupus erythematosus [23,24], vasculitis [26], demyelinating disease [27], immune thrombocytopenic purpura [28] and myasthenia gravis [29]. This is the first report describing an association between MD and polymorphisms of CD16A receptor in mediterranean population, although we could not replicate this effect in the Galicia population. We also previously found that the HLA class II allele DRB1*1101 was associated in mediterranean patients with MD, but not association was found in patients from Galicia [14].

$\mathrm{MD}$ is multifactorial and the interaction of several genes with the environment is probably involved. Several mutations have been described in the coagulation factor $\mathrm{C}$ homology $(\mathrm{COCH})$ gene (14q12-13), which cause the autosomal dominant SNHL DFNA9 (OMIM603196) [30], and a high prevalence of symptoms of MD has been described in European families with a P51S mutation in exon 4 of $\mathrm{COCH}$ gene [31]. However, these mutations were not found in patients with MD [32].

Many tests have been developed for the detection of $\mathrm{CIC}$, including polyethylene glycol (PEG) precipitation and radial immunodiffusion and cellular based assays. No single procedure appears to detect all types of CIC, however, those procedures which detect $\mathrm{CIC}$ containing fragments of complement (e.g. C1q and C3d) appear to detect clinically relevant events. Although several reports have found elevated CIC in 54-96\% of patients with MD using the PEG precipitation assay $[15,16]$, another study using our method, a solid phase immunosorbent assay
(ELISA) for C1q and IgG also found an elevation of CICs in $4 \%$ of 49 patients with MD [34]. Our results confirm this study and found elevated CIC in $7.4 \%$ of 331 patients. Moreover, subanalysis of patients with bilateral MD did not show a higher frequency of elevated CIC. Our data cannot support that pathophysiology of MD is different in patients with uni or bilateral involvement.

Histopathology studies in temporal bones from patients with MD have shown endolymphatic hydrops and vestibular fibrosis in the inner ear. Immunohistochemistry have found deposits of $\mathrm{C} 3$ and $\mathrm{C} 1 \mathrm{q}$ in the membranous labyrinth located at the basal membrane, subepithelial connective tissue, vestibular ganglion and endolymphatic sac of patients with MD [35,36]. It appears that immune injury may be induced in the inner ear at sites where CIC are deposited in the vessels. It is hypothesized that deposits of CIC in the vessels of the stria vascularis may interfere with the recycling of $\mathrm{K}^{+}$ions, resulting in an osmotic imbalance, cellular stress and probably dysfunction of fibrocytes of the spiral ligament. The flux of $\mathrm{K}^{+}$ions into the endolymphatic compartment from the stria vascularis reflects the current flow underlying the endolymphatic potential [37]. In a guinea pig model, it appears that type I fibrocytes and other cells are damaged before the onset of hydrops, but the mechanism is unknown [38].

One of the limitations of this study is that we could not demonstrate an association between patients with the genotype AA of CD16A and elevated CIC. This could be explained because blood samples were not obtained in an acute phase of the disease, and CIC levels may fluctuate within the same patient according to the 
disease activity. Our next study will look at the CIC level during the acute phases of MD to compare them with basal CIC levels in subjects with genotype AA of CD16A.

\section{Conclusions}

Elevated CIC were found in 7\% of patients with MD. Polymorphisms of CD16A (FcyRIIIa*559A > C, rs396991) and CD32A (Fc $\gamma$ RIIa*519A > G, rs1801274) genes are not associated with onset of MD.

\section{Acknowledgements}

This study was supported by a research project FIS PI07/0035. JALE was partially supported by ISCIII research grant INT09/229. The 3130 XL Genetics Analyzer was funded by grant IF06/37291 from Ministry of Science.

\section{Author details}

'Otology \& Neurotology Group CTS495, Department of Otolaryngology, Hospital de Poniente, El Ejido, Almería, Spain. ${ }^{2}$ GENYO, - Centro de Genómica e Investigación Oncológica - Pfizer/Universidad de Granada/Junta de Andalucía, Granada, Spain. ${ }^{3}$ Department of Immunology, Hospital Universitario Virgen de las Nieves, Granada, Spain. ${ }^{4}$ Otology \& Neurotology Group CTS495, Department of Biotechnology, Hospital de Poniente, El Ejido, Almeria. ${ }^{5}$ Division of Otoneurology, Department of Otorhinolaryngology, Complejo Hospitalario Universitario, Santiago de Compostela, Spain. ${ }^{6}$ Department of Otolaryngology, Complejo Hospitalario de Pontevedra, Spain. ${ }^{7}$ Division Otoneurology, Department of Otorhinolaryngology, Hospital La Fe, Valencia, Spain.

\section{Authors' contributions}

JALE and MLN conceived and coordinated the study and draft the manuscript. JALE, ASV, SS, IA and HPG participated in the clinical design of the study, recruited patients with Meniere's disease and collected blood samples for DNA extraction. PSL, IG and AM recruited controls and carried out the genotyping studies. CGO and Al carried out the immunoassays for immunocomplexes. JALE and IG performed the statistical analysis. All authors read and approved the final manuscript.

\section{Competing interests}

The authors declare that they have no competing interests.

Received: 15 June 2010 Accepted: 5 January 2011

Published: 5 January 2011

\section{References}

1. Brand O, Gough S, Heward J: HLA, CTLA-4 and PTPN22: the shared genetic master-key to autoimmunity? Expert Rev Mol Med 2005, 7:1-15.

2. McCabe BF: Autoimmune sensorineural hearing loss. Ann Otol Rhinol Laryngol 1979, 88:585-9.

3. Tebo AE, Szankasi P, Hillman TA, Litwin CM, Hill HR: Antibody reactivity to heat shock protein 70 and inner ear-specific proteins in patients with idiopathic sensorineural hearing loss. Clin Exp Immunol 2006, 146:427-32.

4. Harris JP, Weisman MH, Derebery JM, et al: Treatment of corticosteroidsresponsive autoimmune inner ear disease with methotrexate: a randomized controlled trial. JAMA 2003, 290:1875-83.

5. Amor-Dorado JC, Paco L, Martin J, Lopez-Nevot MA, Gonzalez-Gay MA: Human leukocyte antigen- DQB1 and -DRB1 associations in patients with idiopathic sudden sensorineural hearing loss from a defined population of northwest Spain. Acta Otolaryngol 2005, 125:1277-1282.

6. Hughes $G B$, Kinney $S E$, Barna BP, et al: Autoimmune reactivity in Menière's disease: a preliminary report. Laryngoscope 1983, 93:410-417.

7. Yoo TJ, Shea J Jr, Ge X, et al: Presence of autoantibodies in the sera of Meniere's disease. Ann Otol Rhinol Laryngol 2001, 110:425-9.

8. Fattori B, Nacci A, Dardano A, et al: Possible association between thyroid autoimmunity and Ménière's disease. Clin Exp Immunol 2008, 152:28-32.
9. Lopez-Escamez JA, Saenz-Lopez P, Acosta L, et al: Association of a functional polymorphism of PTPN22 encoding a lymphoid protein phosphatase in bilateral Meniere's disease. Laryngoscope 2010, 120:103-7.

10. Xenellis J, Morrison AW, McClowskey D, Festenstein H: HLA antigens in the pathogenesis of Ménière's disease. J Laryngol Otol 1986, 100:21-24.

11. Arweiler DJ, Jahnke $K$, Grosse-Wilde H: [Ménière's disease as an autosome dominant hereditary disease]. Laryngorhinootologie 1995, 74:512-515.

12. Koyama S, Mitsuishi $Y$, Bibee $K$, Watanabe I: HLA associations with Meniére disease. Acta Otolaryngol (Stockh) 1993, 113:575-578.

13. Yeo SW, Park S, Jeon E, Lee HY, Pyo CW, Ki TG: Influence of human leucocyte antigen in the pathogenesis of Meniere's disease in the south korean population. Acta Otolaryngol 2002, 122:851-56.

14. Lopez-Escamez JA, Vilchez JR, Soto-Varela A, et al: HLA-DRB1*1101 allele may be associated with bilateral Meniere's disease in southern european population. Otol Neurotol 2007, 28:891-5.

15. Brookes GB: Circulating immune complexes in Meniere's disease. Arch Otolaryngol Head Neck Surg 1986, 112:536-540.

16. Derebery MJ, Rao VS, Siglock TJ, Linthicum FH, Nelson RA: Meniere's disease: an immune complex-mediated illness? Laryngoscope 1991, 101:225-229.

17. Van Sorge NM, Van der Pol W-L, Van de Winkel JGJ: Fcy polymorphisms: implication for function, disease susceptibility and immunotherapy. Tissue Antigen 2003, 61:189-202.

18. Van der Pol WL, vande Winkel JGJ: IgG receptor polymorphisms: risk factors for disease. Immunogenetics 1998, 48:222-32.

19. Wu J, Edberg JC, Redecha PB: A novel polymorphism of FcgammaRIlla (CD16) alters receptor function and predisposes to autoimmune disease. J Clin Invest 1997, 100:1059-70.

20. Parren PW, Warmerdam PA, Boeije LC, et al: On the interaction of IgG subclasses with the low affinity Fc gamma Rlla (CD32) on human monocytes, neutrophils and platelets. Analysis of a functional polymorphism to human IgG2. J Clin Invest 1992, 90:1537-46.

21. Nieto A, Caliz R, Pascual M, Matarán L, Garcia S, Martin J: Involvement of Fcy receptor IIIA genotypes in susceptibility to rheumatoid arthritis. Arthritis Rheum 2000, 43:735-9.

22. Morgan AW, Griffiths B, Ponchel F, et al: Fcgamma receptor type IIIA is associated with rheumatoid arthritis in two distinct ethnic groups. Arthritis Rheum 2000, 43:2328-34.

23. Dijstelbloem HM, Bijl M, Fijnheer $R$, et al: Fcgamma receptor polymorphisms in systemic lupus erythematous: association with disease and in vivo clearance of immune complexes. Arthritis Rheum 2000, 43:2793-800.

24. Edberg JC, Langefeld CD, Wu J, et al: Genetic linkage and association of Fcgamma receptor IIIA (CD16A) on chromosome 1q23 with human systemic lupus erythematosus. Arthritis Rheum 2002, 46:2132-40.

25. Committee on Hearing and Equilibrium: Guidelines for the diagnosis and evaluation of therapy in Meniere's disease. Otolaryngol Head Neck Surg 1995, 113:181-185.

26. Aksu K, Kitapcioglu G, Keser G, et al: FcgammaRIla, Illa and IIlb gene polymorphisms in Behcet's disease: do they have any clinical implications? Clin Exp Rheumatol 2008, 4(Suppl 50):S77-83.

27. Van der Pol WL, van der Berg LH, Scheepers $\mathrm{RH}$, et al: IgG receptor Ila alleles determine susceptibility and severity of Guillain-Barre syndrome. Neurology 2000, 54:1661-5.

28. Cines DB, McMillan R: Pathogenesis of chronic immune thrombocytopenic purpura. Curr Opin Hematol 2007, 14:511-4.

29. Raknes G, Skeie GO, Gilhus NE, Aadland S, Veleder C: FcgammaRIIA and FcgammaRIIIB polymorphisms in myasthenia gravis. J Neuroimmunol 1998, 81:173-6.

30. Robertson NG, Lu L, Heller S, et al: Mutations in a novel Cochlear gene cause DFNA9, a human nonsyndromic deafness with vestibular dysfunction. Nat Genet 1998, 20:299-303.

31. Fransen $E$, Verstreken $M$, Verhagen Wl, et al: High prevalence of symptoms of Meniere's disease in three families with a mutation in the $\mathrm{COCH}$ gene. Hum Mol Genet 1999, 8:1425-1429.

32. Sanchez E, Lopez-Escamez JA, Lopez-Nevot MA, Lopez-Nevot A, Cortes R, Martin J: Absence of $\mathrm{COCH}$ mutations in patients with Meniere disease. Eur J Hum Gen 2004, 12:75-8.

33. Savastano M, Giacomelli L, Marioni G: Non-specific immunological determinations in Meniere's disease: any role in clinical practice? Eur Arch Otorhinolaryngol 2007, 264:15-19. 
34. Perez Garrigues H, Carmona E, Morera C, Sanchez-Cuenca JM: Circulating auto-antibodies in Meniere's disease. Ann Otolaryngol Chir Cervicofac 1995, 112:225-228.

35. Hausler R, Arnorld W, Schfferlic J: C3 and C1q complement deposits in the membranous labyrinth of patients with Meniere's disease. Adv Otorhinolaryngol 1988, 42:116-122.

36. Yazawa $Y$, Kitahara M: Immunofluorescent study of the endolymphatic sac in Meniere's disease. Acta Otolaryngol (Stockh) 1989, 468(Suppl):71-76.

37. Salt AN: Regulation of endolymphatic fluid volume. Ann NY Acad Sci 2001, 942:306-312.

38. Shinomori Y, Kimura RS, Adams JC: Changes in immunostaining for $\mathrm{Na}$, $\mathrm{K}+, 2 \mathrm{Cl}$-cotransporter 1 , taurine and c-Jun $\mathrm{N}$-terminal kinase in experimentally induced endolymphatic hydrops. ARO Abstract 2001, 24:134.

\section{Pre-publication history}

The pre-publication history for this paper can be accessed here: http://www.biomedcentral.com/1471-2350/12/2/prepub

doi:10.1186/1471-2350-12-2

Cite this article as: Lopez-Escamez et al:: Polymorphisms of CD16A and CD32 Fcy receptors and circulating immune complexes in Ménière's disease: a case-control study. BMC Medical Genetics 2011 12:2.

\section{Submit your next manuscript to BioMed Central} and take full advantage of:

- Convenient online submission

- Thorough peer review

- No space constraints or color figure charges

- Immediate publication on acceptance

- Inclusion in PubMed, CAS, Scopus and Google Scholar

- Research which is freely available for redistribution

Submit your manuscript at www.biomedcentral.com/submit 